\title{
Dynamic Performance Enhancement of a Grid- Connected Wind Farm Using Doubly Fed Induction Machine-Based Flywheel Energy Storage System
}

\author{
${ }^{1}$ T.A. Taj, ${ }^{1}$ Hany M. Hasanien, ${ }^{1}$ A.I. Alolah \\ Department of Electrical Engineering, \\ College of Engineering \\ King Saud University \\ Riyadh, Saudi Arabia \\ ttaj@ksu.edu.sa, hanyhasanein@ieee.org
}

\author{
${ }^{2}$ S.M. Muyeen \\ Electrical Engineering Department, \\ The Petroleum Institute \\ Abu Dhabi 2533, U.A.E.
}

\begin{abstract}
This paper presents the dynamic performance enhancement of a wind farm connected to an IEEE-39 bus New England test system using doubly-fed induction machine (DFIM)-based flywheel energy storage system (FESS). The variable wind speed causes fluctuations in the output power of the wind farms. The use of FESS smoothes the power of the wind farm and improves the dynamic response of the system during fluctuating wind speeds. A DFIM-based FESS is proposed in this study which works on an effective control technique. The cascaded black-box optimization technique based proportional-integral (PI) control strategy is implemented on the FESS. The PI controllers are used to control the insulated gate bipolar transistor (IGBT) based rotor side converter (RSC) and the grid side converter (GSC) of the DFIM. The PI controller In-depth modeling and control strategy of the system under study is presented. The effectiveness of the proposed system is tested under real-time wind speed data. The validity of the system is verified by the simulation results which are carried out using PSCAD/EMTDC.
\end{abstract}

Index Terms---- Doubly fed induction machine, flywheel energy storage system, PI controller, variable wind speed, wind farm

\section{INTRODUCTION}

$\mathrm{D}$ epletion of fossil fuel, increase in oil prices and growth in energy demand are the significant reasons to transfer from classical energy sources to renewable energy [1]. Among several renewable energy sources, which includes, solar, wind, biogas, geothermal and ocean energy, wind energy has become the fastest growing which is expected to reach a installed capacity of $600 \mathrm{GW}$ by 2018 [2]. The wind energy has a significant share in total power produced all over the world. The major issue in the generation of wind power is the variable nature of wind speed. The continuously changing wind speed has a big impact on the power output of the wind farm. A minor change in the wind speed causes a significant variation on the output of the wind farm [3]. Hence, it is necessary to improve the dynamic response of the wind farm by mitigating the fluctuations of wind generator output power [3]. The smoothing of output power of the wind farm also improve the quality of the power delivered to the grid.
The dynamic performance enhancement of wind farm can be achieved by using different kinds of energy storage devices (ESSs). In general, Battery energy storage system (BESS), superconducting magnetic energy storage (SMES) systems, energy capacitor systems (ECS) or flywheel energy storage systems (FESS) etc. [3]-[8] are used to smooth the output power of the wind farm.

In this work, the use of FESS to mitigate power fluctuation of a wind farm is presented. The main advantages of FESS include greater power and energy density as compared to other energy storage devices (ESS) and long life span [9]-[12]. Moreover, low installation and maintenance cost makes FESS a better choice than other ESSs. Due to these benefits, a FESS is used in dynamic and transient stability enhancement of the power systems.

The FESS are widely used as energy buffers in order to transfer or exchange energy to and from a power generation system [13]-[15]. One of the major applications of FESS is in wind energy conversion system (WECS). They are used to mitigate the fluctuations in the power produced by the wind turbine system (WTS) due to variable wind speed. The variable nature of wind speed can produce undesirable variations on the power or voltages to the grid.

Both induction and permanent-magnet (PM) machines are used as FESS for energy storage and power smoothing applications [16]. In this study a doubly fed induction machine (DFIM) is used as FESS. The major advantage of using DFIM-based FESS is that it acts as a reactive power compensator [3]. Also, a small capacity FESS is cheaper as compared to other ESS. Moreover, it requires a lesser capacity power converter which simplify the design of the system. Hence, FESS with an efficient control strategy effectively improves the dynamic performance and stability of the system.

The DFIM-based FESS can improve the power system stability of wind generator systems [17]. The classical PI controllers are widely used to improve the dynamic performance of the grid connected wind farm [3]. The PI controller is the most commonly used in the industry due to its robustness and offering wide stability margins. 
Therefore, this paper presents the dynamic stability enhancement of a grid connected wind farm using a DFIM based FESS. The controlling of the FESS is performed through cascaded black-box optimization technique based PI-controllers [18, 19]. Modeling of system including the control strategy for the proposed model is explained. Simulation results are investigated thoroughly. The validity of the proposed model is verified through simulation using the standard dynamic power system simulator PSCAD/EMTDC [20].

The organization of the paper is given as follows: Section II contains the modeling of wind turbine and DFIM. Section III describes the FESS configuration. In Section IV, controlling scheme to improve the dynamic performance of the system is explained. Simulation results are presented in Section V. Section VI concludes the paper.

\section{SYSTEM MODELING}

The wind farm consists of five induction wind generator each of 2 MVA. The aggregated model is connected to an IEEE-39 bus New England test system. The IEEE 39 bus system contains 39 buses out of which 19 are load buses. There are 10 generators in the system. The total load and generation in the system are 6098.1 MW and 6140.81 MW, respectively. The power generation for the 10 generators varies from $250 \mathrm{MW}$ to $1000 \mathrm{MW}$ [21]. In order to test the proposed FESS with the IEEE-39 bus system, Generator 10 connected at bus 30 which is producing $250 \mathrm{MW}$ is replaced by the wind farm which is connected to the FESS at the point of common coupling (PCC). The variable wind speed data is taken from Electric Machine LAB, Kitami Institute of Technology, Japan.

\section{A. Wind Turbine Modeling}

The mechanical power produced by the wind turbine is expressed as follows [22]-[24]:

$$
P_{w}=\frac{1}{2} \rho \pi R^{2} V_{w}^{3} C_{P}(\lambda, \beta)
$$

where, $P_{w}$ is the extracted power from the wind, $\rho$ is the air density $\left[\mathrm{kg} / \mathrm{m}^{3}\right], R$ is the blade radius $[\mathrm{m}], V_{w}$ is the wind speed $[\mathrm{m} / \mathrm{s}]$, and $C_{p}$ is the power coefficient which is a function of tip speed ratio, $\lambda$, and blade pitch angle, $\beta$ [deg.]. The model system shown in Fig. 1 is used for simulation in this paper.

\section{B. Modeling of DFIM as FESS}

The DFIM can be modeled by the following equations [25] in the direct $(d)$ and quadrature $(q)$ axis reference frame, which is rotating at synchronous speed $(\omega=2 \pi f)$. The stator and rotor voltages are written as follows:

$$
\begin{aligned}
& U_{s d}=-R_{s} i_{s d}-p \psi_{s d}+\omega_{1} \psi_{s q} \\
& U_{s q}=-R_{s} i_{s q}-p \psi_{s q}-\omega_{1} \psi_{s d} \\
& U_{r d}=R_{r}{ }_{r}{ }_{r d}+p \psi_{r d}-p \theta_{s} \psi_{r q} \\
& U_{r q}=R_{r}{ }_{r q}{ }_{r q}+p \psi_{r q}+p \theta_{s} \psi_{r d}
\end{aligned}
$$

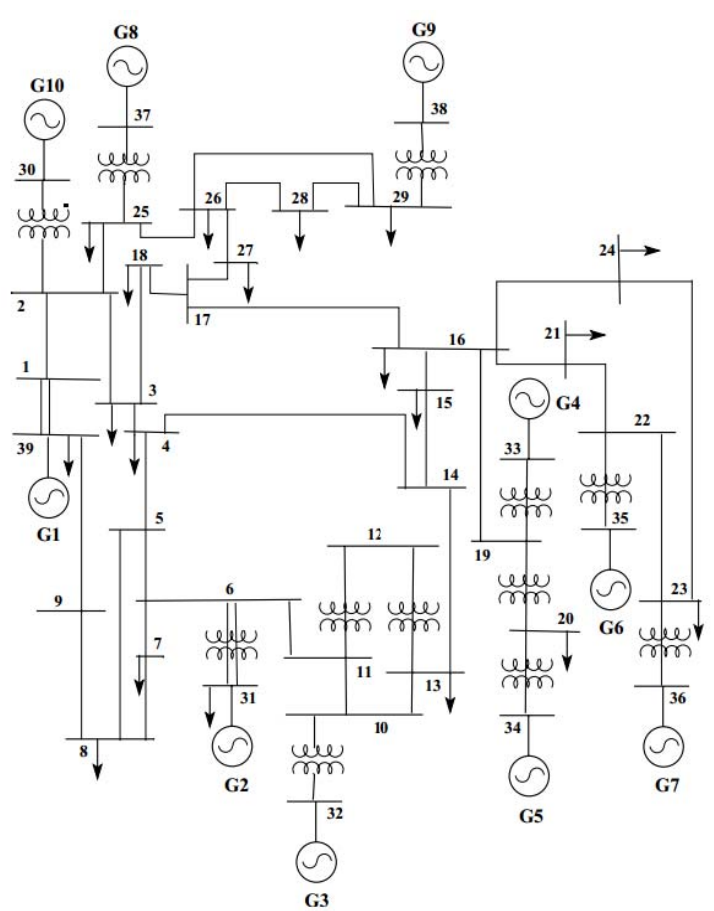

Fig. 1 Model System

Stator and rotor flux are represented as;

$$
\begin{aligned}
& \psi_{s d}=L_{s i s d}^{i}-L_{m}^{i} r d \\
& \psi_{s q}=L_{s i s q}^{i}-L_{m}{ }^{i} r q \\
& \psi_{r d}=L_{r r d}^{i}-L_{m s d}^{i} \\
& \psi_{r q}=L_{r}{ }_{r}^{i}{ }_{r q}-L_{m}{ }^{i} s q
\end{aligned}
$$

The stator power is;

$$
\begin{aligned}
& P_{s}=U_{s d}{ }_{s d}+U_{s q}{ }^{i} s q \\
& Q_{s}=U_{s q}{ }^{i}{ }_{s d}-U_{s d}{ }^{i}{ }_{s q}
\end{aligned}
$$

Rotor swing equation is;

$$
T_{m}-T_{e}=-T_{e}=\frac{J}{n_{P}} \frac{d \omega_{r}}{d t}+\frac{D}{n_{P}} \omega_{r}
$$

where, $U$ is the voltage, $R$ is the resistance, $i$ is the current, $L$ is inductance, $\psi$ is the flux linkage. $\omega_{l}$ and $\omega_{r}$ are the stator and rotor electrical angular speed, respectively. $D$ is the damping torque, $T_{m}$ is mechanical torque, $T_{e}$ is the developed torque, $n_{P}$ and $J$ are considered as number of pole pairs and rotor inertia. $\theta_{s}$ is the angle between rotor phase A-axis to the d-axis. And $s, r$, and $m$ indicate stator, rotor and mutual quantities, respectively.

\section{FESS CONFIGURATION}

The principle of working of FESS is that it stores the energy in the flywheel (rotor) of the DFIM and exchange the power with the system during variable wind speed conditions. The FESS is configured in such a way that the stator windings of the DFIM is connected to the grid directly while the rotor winding is coupled with the IGBT based frequency converter. The RSC is connected directly to the rotor winding of the DFIM. Fig. 2 represents the DFIM based FESS and its control strategy. 


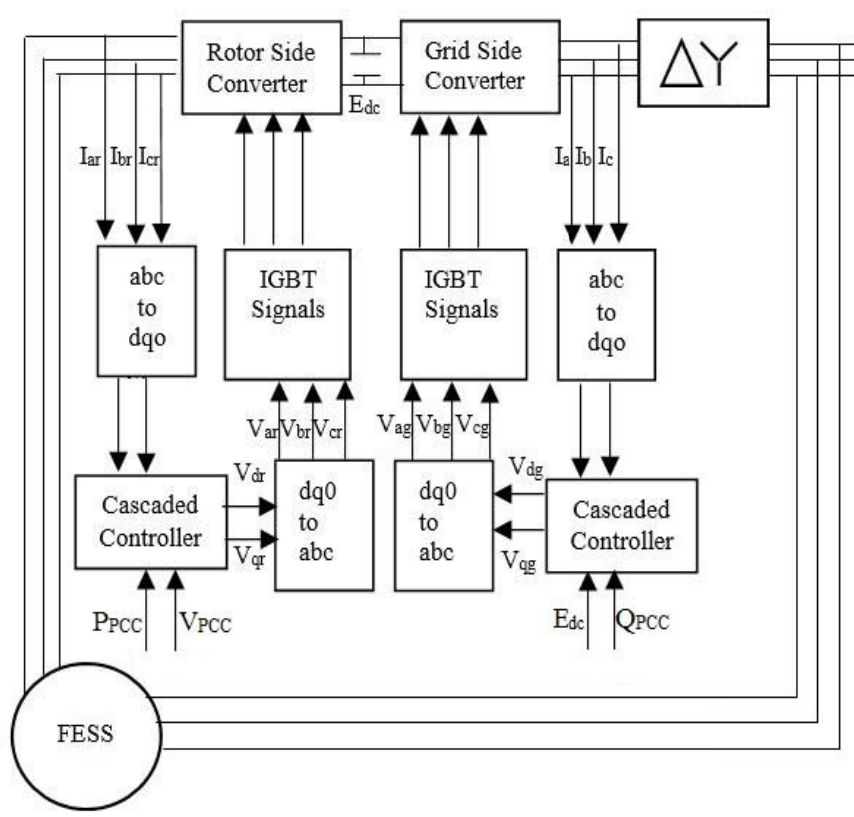

Fig. 2 Model for FESS

\section{Proposed Control Strategy}

A small capacity FESS can be used with an effective control strategy to smooth the output power of a gridconnected wind farm. In this study, the control of both GSC and RSC is performed through cascaded PI controllers. There are 2 sets of cascaded PI controllers for GSC and RSC. The dc-link voltage $\left(E_{d c}\right)$ and the reactive power $\left(Q_{P C C}\right)$ of the wind farm are controlled through the GSC while the RSC controls the real power $\left(P_{P C C}\right)$ and voltage of the wind farm $\left(V_{P C C}\right)$. Fig. 3(a) and (b) shows the cascaded PI control strategy for the GSC and RSC.

The outputs of all four cascaded controllers $\mathrm{V}_{d g}, \mathrm{~V}_{q g}, \mathrm{~V}_{d r}$ and $\mathrm{V}_{q r}$ are transformed from dq0 to abc frame and then sent to the comparator which generates the control signal for the respective IGBT switches as shown in Fig. 4(a) and (b). The carrier frequency of the reference triangular wave is chosen to be $2 \mathrm{kHz}$. The dc-link voltage across the 2000 $\mu \mathrm{F} \mathrm{dc}-$ link capacitor is to be maintained at $4 \mathrm{kV}$.

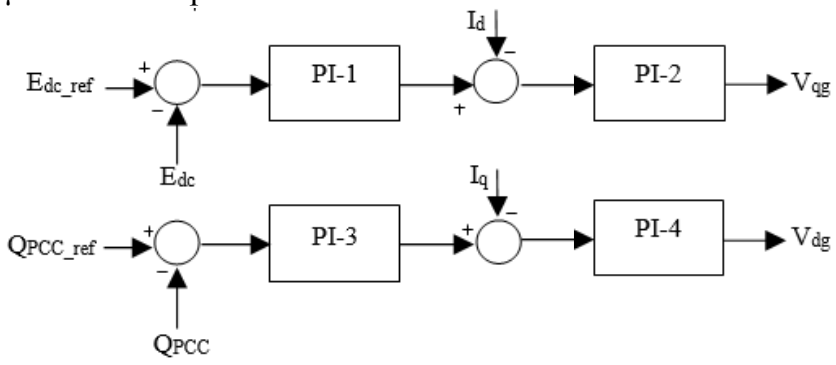

Fig. 3(a) Cascaded PI control for controlling the GSC

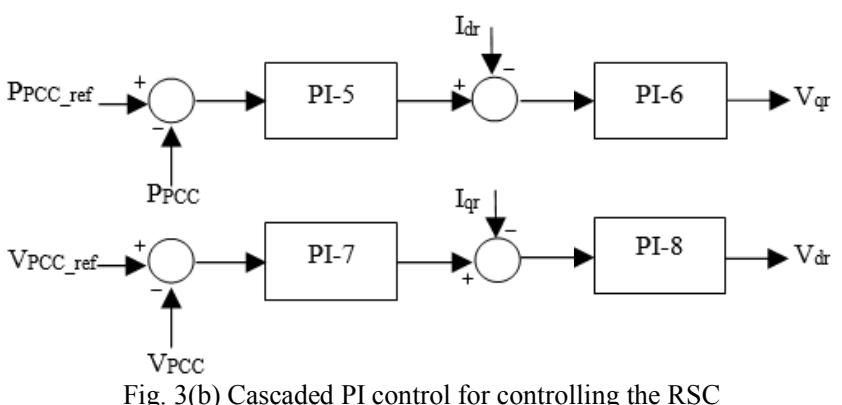

Fig. 3(b) Cascaded PI control for controlling the RSC

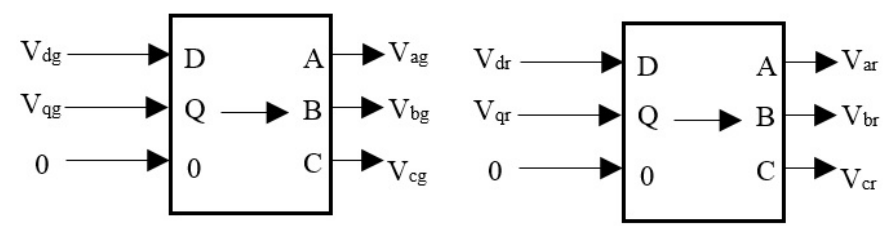

Fig. 4(a) dq0 to abc transformation of the voltages for GSC and RSC

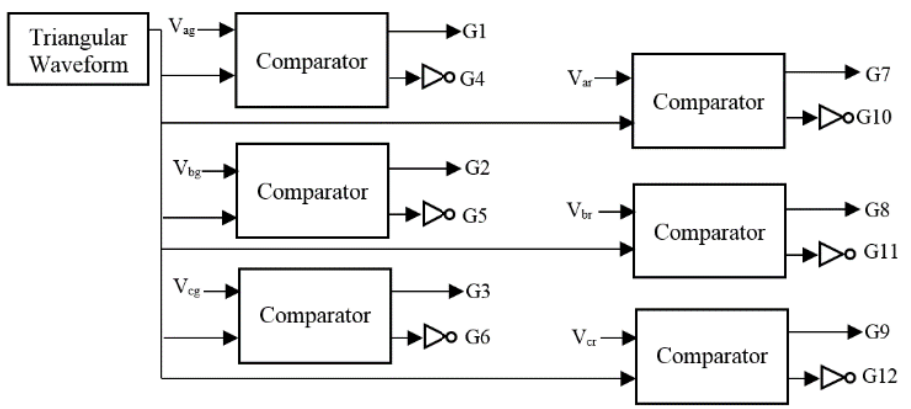

Fig. 4(b) Generation of gate signals for IGBT switches

\section{Simulation Results}

In this paper a DFIM-based FESS is presented to improve the dynamic performance of a grid-connected wind farm. The simulation of the model under study and its dynamic stability analysis are performed through PSCAD/EMTDC. The simulation time is $500 \mathrm{~s}$ and the solution time step is $20 \mu$ s. The dynamic stability of the system is analyzed through variable wind speed. The parameters of the PIcontroller are optimized using the black-box optimization technique.

The real power out of the PCC without FESS is shown in Fig. 5. It can be noted in Fig. 5 that without the FESS, the real power out of the PCC is fluctuating excessively with the change of wind speed and do not reach the desired reference value. The real power out of the PCC is increasing and decreasing with respect to the wind speed. The dynamic performance of the system is improved significantly when the FESS is coupled with the PCC. Fig. 6(a) to (g) shows the response of the system with FESS. The FESS compensates the real and reactive power immediately and smoothes the output of the wind farm. The real and reactive power returns back to the reference values as shown in Fig. 6(a) and (b). It can be seen in Fig. 6(c) and (d) that the IG and turbine speeds become stable with minimum oscillations. Moreover, the voltage at the PCC also regains the reference value effectively as shown in Fig. 6(e). Fig 6(f) shows the dc-link voltage. The power of the FESS in Fig. $6(\mathrm{~g})$ shows the continuous exchange of active power between the system and the FESS to smooth the output power of the wind farm.

The simulation results prove that the wind turbine IG system become stable using FESS. The system responses using FESS are better than that of without FESS. Therefore, FESS is considered to be an effective means for enhancing the dynamic performance of the wind turbine IG systems. 


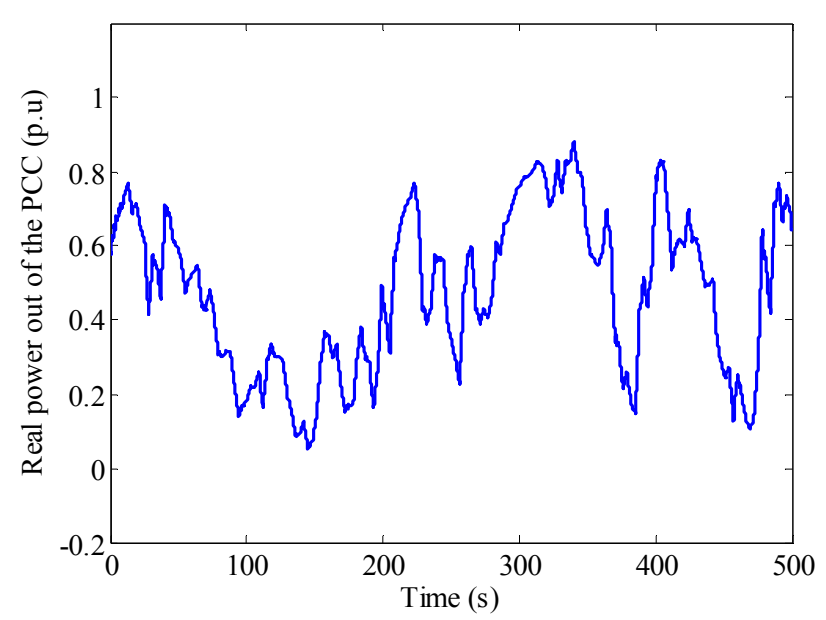

Fig. 5 Real power out of the PCC without FESS

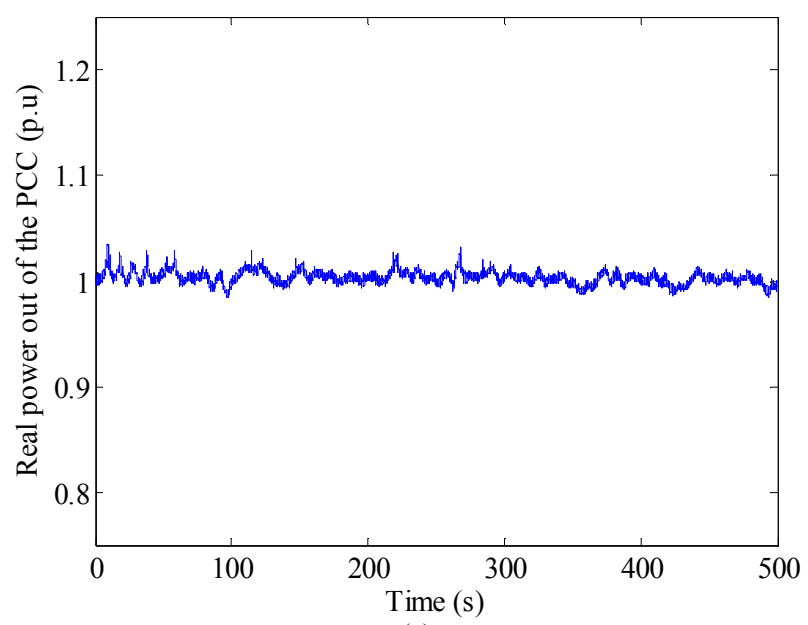

(a)

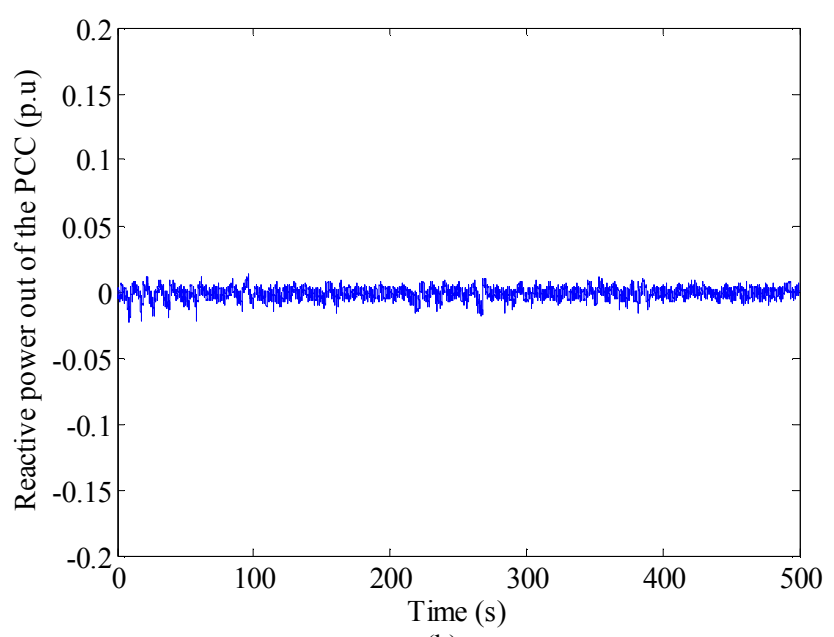

(b)

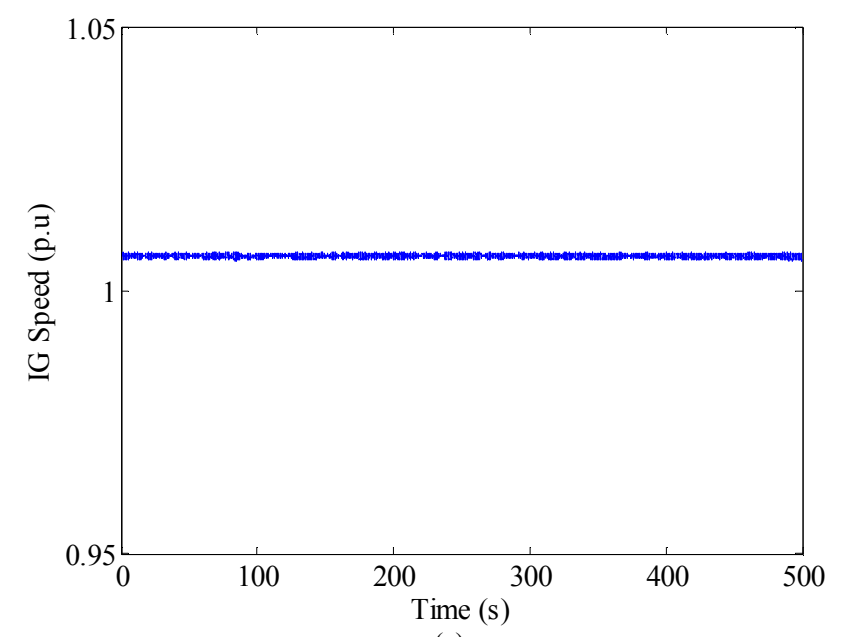

(c)

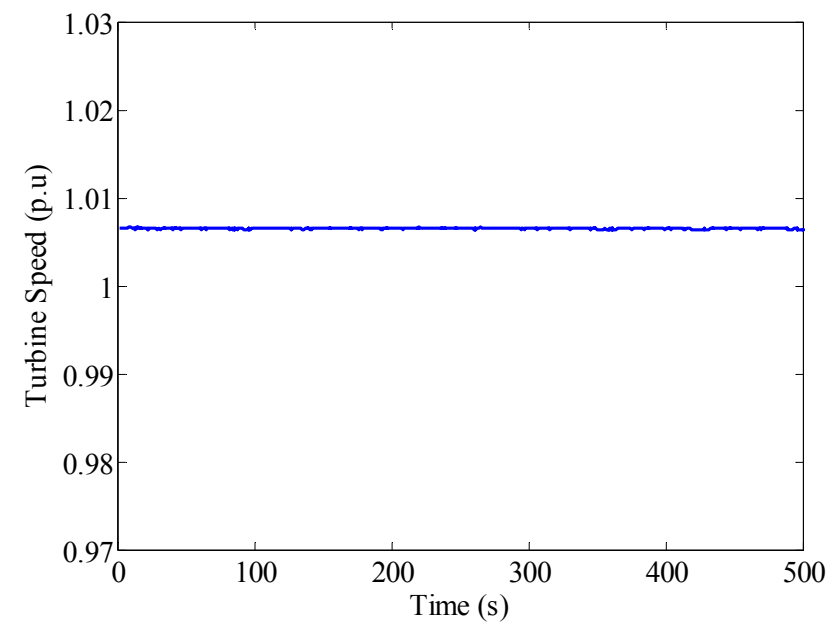

(d)

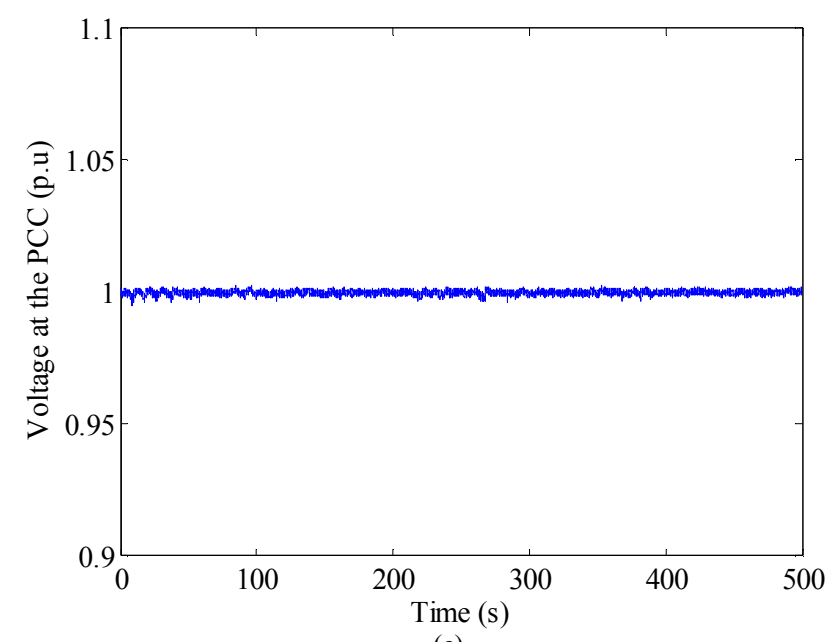

(e) 


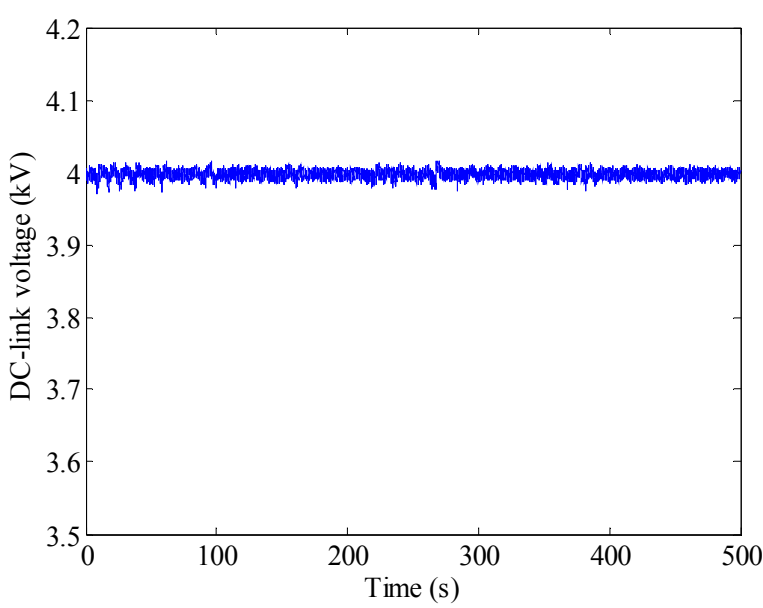

(f)

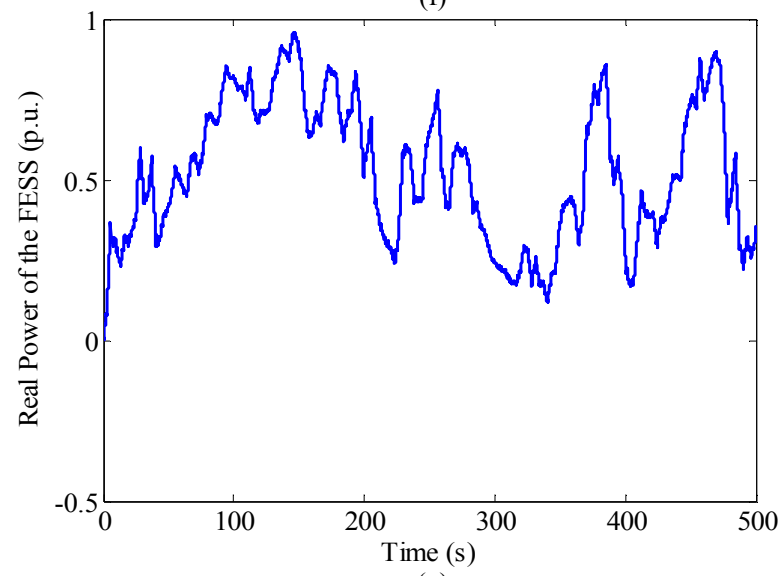

(g)

Fig. 6. System response with FESS. (a) Real power out of the PCC (b) Reactive power out of the PCC (c) IG speed (d) Turbine speed (e) Voltage at the PCC (f) dc-link voltage (g) Real power of FESS

\section{CONCLUSION}

A FESS with an effective cascaded PI control strategy was presented in this study to improve the dynamic performance of the wind farm connected to an IEEE 39 bus system. The system is tested under real-time variable wind speed data. The black-box optimization technique based PI control strategy works effectively and system returns back to the desired reference values under variable wind speed. The controlling technique indicated a better system performance when compared to the system without the FESS. Hence, it is clear from this study that a FESS with a proper and efficient control strategy improves the dynamic performance of the grid-connected wind farm.

\section{ACKNOWLEDGEMENT}

The authors would like to thank the Deanship of Scientific Research, Research Center at College of Engineering, King Saud University.

\section{REFERENCES}

[1] C. Millais and S. Teske, "Wind Force 12: A blueprint to achieve $12 \%$ of the world's electricity from wind power by 2020", Tech. Report, The European Wind Energy Association, 2004.

[2] Global Wind Energy Council (GWEC), "Wind is a global power source," Global Trend-GWEC, online: http://www.gwec.net, Jan 2014.

[3] F. Islam, H.M. Hasanien, A. Al-Durra, S.M. Muyeen, "A new control strategy for smoothing of wind farm output using short-term ahead wind speed prediction and Flywheel energy storage system," American Control Conference (ACC), pp. 3026-3031, 27 29 June 2012
[4] S.M. Muyeen, H.M. Hasanien, A. Al-Durra, "Transient stability enhancement of wind farms connected to a multi-machine power system by using an adaptive ANN-controlled SMES", Energy Conversion and Management, vol. 78, pp. 412-420, February 2014.

[5] H.M. Hasanien, S.Q. Ali, S.M. Muyeen, "Wind generator stability enhancement by using an adaptive artificial neural networkcontrolled superconducting magnetic energy storage," 15th International Conference on Electrical Machines and Systems (ICEMS), pp.1-6, 21-24 October 2012.

[6] S.M. Muyeen, H.M. Hasanien, J. Tamura, "Reduction of frequency fluctuation for wind farm connected power systems by an adaptive artificial neural network controlled energy capacitor system," IET Renewable Power Generation, vol. 6, no. 4, pp.226-235, July 2012.

[7] S.M. Muyeen, M.H. Ali, R. Takahashi, T. Murata, J. Tamura, "Wind Generator Output Power Smoothing and Terminal Voltage Regulation by Using STATCOM/ESS," IEEE Power Tech, Lausanne, pp. 1232-1237, 1-5 July 2007.

[8] R. Takahashi and J. Tamura, "Frequency Control of Isolated Power System with Wind Farm by using Flywheel Energy Storage System," International Conference on Electrical Machines, Paper ID 1410 , 2008.

[9] H. Akagi, and H. Sato, "Control and performance of a doubly-fed induction machine intended for a flywheel energy storage system", IEEE Transactions Power Electronics, vol. 17, no. 1, pp. 109-116, 2002.

[10] R. Cardenas, R. Pena, G. Asher, and J. Clare, "Control strategies for enhanced power smoothing in wind energy systems using a flywheel driven by a vector-controlled induction machine", IEEE Transactions on Industrial Electronics, vol. 48, no. 3, pp. 625-635, 2001.

[11] R. Hebner, J. Beno, and A. Walls, "Flywheel batteries come around again", IEEE Spectr., pp. 46-51, 2002.

[12] R.S. Weissbach, G.G. Karady, and R.G. Farmer, "Dynamic voltage compensation on distribution feeders using flywheel energy storage", IEEE Transactions on Power Delivery, vol. 14, no. 2, pp. 165-170, 1999.

[13] R. Cárdenas, R. Peña, G. Asher, and J. Clare, "Control strategies for enhanced power smoothing in wind energy systems using a flywheel driven by a vector controlled induction machine," IEEE Transactions on Industrial Electronics, vol. 48, pp. 625-635, June 2001.

[14] J. A. M. Bleij, A. W. K. Chung, and J. A. Rudell, "Power smoothing and performance improvement of wind turbines with variable speed," Proc. 17th BWEA, Warwick, U.K., 1995, pp. 353-358.

[15] A. J. Rudell, J. A. M. Bleij, and L. Freris, "A wind diesel system with variable speed flywheel storage," Wind Energy, vol. 17, no. 3, pp. 129-145, 1993.

[16] Cárdenas, Roberto, et al. "Control strategies for power smoothing using a flywheel driven by a sensorless vector-controlled induction machine operating in a wide speed range." IEEE Transactions on Industrial Electronics, vol. 51, no. 3, pp 603-614, 2004.

[17] Kairous, D.; Wamkeue, R.; Belmadani, B., "Sliding mode control of DFIG based variable speed WECS with flywheel energy storage," XIX International Conference on Electrical Machines (ICEM), pp.1-6, 6-8 Sept. 2010.

[18] Jones, Donald R., Matthias Schonlau, and William J. Welch. "Efficient global optimization of expensive black-box functions," Journal of Global optimization, vol. 13, no. 4, pp. 455-492, 1998.

[19] H.M. Hasanien, M. Matar, “A Fuzzy Logic Controller for Autonomous Operation of a Voltage Source Converter-Based Distributed Generation System," IEEE Transactions on Smart Grid, vol. 6, no. 1, pp. 158-165, Jan. 2015.

[20] PSCAD/EMTDC Manual v 4.5, Manitoba HVDC Research Center, 2014.

[21] V. Togiti, "Pattern Recognition of Power System Voltage Stability using Statistical and Algorithmic Methods," University of New Orleans Theses and Dissertations, Paper 1488, 2012.

[22] H.M. Hasanien, "A Set-Membership Affine Projection AlgorithmBased Adaptive-Controlled SMES Units for Wind Farms Output Power Smoothing”, IEEE Transactions on Sustainable Energy, vol. 5, no. 4, pp. 1226-1233, Oct. 2014.

[23] H.M. Hasanien, "Shuffled frog leaping algorithm-based static synchronous compensator for transient stability improvement of a grid-connected wind farm," Renewable Power Generation, IET, vol. 8, no. 6, pp. 722-730, August 2014

[24] H.M. Hasanien, and S.M. Muyeen, "Design Optimization of Controller Parameters used in Variable Speed Wind Energy Conversion System by Genetic Algorithms", IEEE Transactions on Sustainable Energy, vol. 3, no. 2, pp. 200-208, April 2012.

[25] G. Li, S. Cheng, J. Wen, Y. Pan and J. Ma, "Power System Stability Enhancement by a Double-fed Induction Machine with a Flywheel Energy Storage System," IEEE Power Engineering Society General Meeting, 2006 